\title{
PRECIPITAÇÃO EFETIVA E INTERCEPTAÇÃO DA CHUVA EM UM FRAGMENTO FLORESTAL COM DIFERENTES ESTÁGIOS DE REGENERAÇÃO ${ }^{1}$
}

\author{
Alexandre Simões Lorenzon², Herly Carlos Teixeira Dias³ e Hélio Garcia Leite ${ }^{3}$
}

\begin{abstract}
RESUMO - Este trabalho teve por objetivo avaliar a precipitação efetiva e a interceptação da chuva em um fragmento de Floresta Estacional Semidecidual em estágio inicial e avançado de regeneração no Município de Viçosa, Minas Gerais, no período de agosto de 2009 a fevereiro de 2011. Foram demarcadas seis parcelas, três na área de regeneração inicial e três na área de regeneração avançada. Para quantificar a precipitação interna e o escoamento pelo tronco, foram instalados 25 pluviômetros em cada parcela e coletores nas árvores com circunferência $\geq 15 \mathrm{~cm}$. Além disso, um pluviômetro foi instalado em local aberto para quantificar a precipitação em aberto, que no período estudado foi igual a 1.509,96 mm. Em média, 85,08 e 74,93\% da precipitação em aberto, respectivamente, no estágio inicial e avançado de regeneração, chegam ao solo via precipitação efetiva. A interceptação pelo dossel florestal foi maior na área avançada do que na área inicial de regeneração, correspondendo, respectivamente, a 25,07 e 14,92\% da precipitação em aberto, o que sugere que áreas mais densamente povoadas interceptam maior quantidade de chuva e, consequentemente, geram menor precipitação efetiva.
\end{abstract}

Palavras-chave: Mata Atlântica; Hidrologia florestal; Manejo de Bacias Hidrográficas.

\section{NET PRECIPITATION AND INTERCEPTION IN A FOREST FRAGMENT WITH DIFFERENT STAGES OF REGENERATION}

\begin{abstract}
The objective of this study was to evaluate the net precipitation and the interception in a fragment of semi deciduous forest both at initial and advanced stages of regeneration in in Viçosa, Minas Gerais, from August 2009 to February 2011. Six plots were demarcated: three in the initial, and three in the advanced regeneration areas, respectively. To quantify the throughfall and the stemflow, 25 rain gauges and gatherers were installed in trees with $\geq 15 \mathrm{~cm}$ circumference in each plot. In addition, a rain gauge was installed in an open area to quantify the unobstructed precipitation. The gross precipitation in the period studied was of $1509.96 \mathrm{~mm}$. On average, 85.08 and $74.93 \%$ of the gross precipitation, for initial and advanced stages of precipitation, respectively, reach the soil via net precipitation. The interception by the forest canopy was greater in the advanced than in the initial regeneration area, corresponding to 25.07 and $14.92 \%$ of the open area precipitation, respectively, suggesting that the more densely populated areas intercept greater rainfall, and consequently, generate less net precipitation.
\end{abstract}

Keywords: Atlantic Forest; Forest hydrology; Watershed management.

\footnotetext{
${ }^{1}$ Recebido em 10.12.2012 aceito para publicação em 06.08.2013.

${ }^{2}$ Programa de Pós-Graduação em Ciência Florestal na Universidade Federal de Viçosa, UFV, Brasil. E-mail: <alelorenzon@yahoo.com.br>.

${ }^{3}$ Departamento de Engenharia Florestal da Universidade Federal de Viçosa, MG, Brasil. E-mail: <herly@ufv.br>e <hgleite@ufv.br>.
} 


\section{INTRODUÇÃO}

A água é um dos elementos mais importantes na composição da paisagem terrestre, interagindo com a fauna e a flora e com os demais elementos da natureza (BALBINOT et al., 2008). Por apresentar estreita relação com o ciclo hidrológico, a floresta é considerada a ocupação de solo que mais beneficia os recursos hídricos. A floresta atua no ciclo hidrológico, provocando o retardamento da movimentação da água da chuva em direção aos rios, através do processo de interceptação, infiltração, absorção, transpiração e percolação (CASTRO et al., 1983), além de minimizar os efeitos erosivos, a lixiviação de nutrientes do solo e o assoreamento dos corpos d'água.

Uma das principais influências da floresta ocorre já no recebimento das chuvas pelas copas das árvores, quando se dá o primeiro fracionamento da água, em que parte fica temporariamente retida pela copa das árvores, no processo denominado interceptação (ARCOVA et al., 2003), e parte atinge o solo florestal, no processo denominado precipitação efetiva, que é a soma da precipitação interna e do escoamento pelo tronco (LIMA, 1975).

A precipitação interna é a água da chuva que atinge o piso florestal, incluindo gotas que passam diretamente pelas aberturas entre as copas das árvores e as gotas que respigam do dossel. A fração da chuva retida temporariamente pelas copas, juntamente com aquela que atinge diretamente os troncos e posteriormente escoam pelo tronco das árvores, chegando ao solo, é denominada escoamento pelo tronco (OLIVEIRA JUNIOR; DIAS, 2005; SHINZATO et al., 2011).

Segundo Alves et al. (2007), a precipitação efetiva pode variar em função de fatores como: área basal, espécie, diâmetro das árvores, densidade de espécies, frequência e intensidade das chuvas. Para Moura et al. (2009), os fatores-chave que influenciam na interceptação e nos demais componentes do balanço hídrico são: formato da cobertura vegetal, área foliar e estrutura da casca.

Valores de precipitação efetiva e interceptação são peculiares ao local, podendo variar dentro do mesmo ecossistema, entre fragmentos próximos ou até dentro de um mesmo fragmento em virtude do estágio de regeneração da floresta. Para a Mata Atlântica, alguns resultados de interceptação e precipitação efetiva mostram valores médios de 12,4 e 87,6\% (CASTRO et al., 1983), 37,6 e 62,4\% (LIMA; LEOPOLDO, 1999), 18,3 e 81,7\% (OLIVEIRA JUNIOR; DIAS, 2005) e 24,8 e 75,2\% (TOGASHI et al., 2012), respectivamente.

O objetivo deste trabalho foi avaliar a precipitação efetiva e a interceptação da chuva em um fragmento de Floresta Estacional Semidecidual em estágio inicial e avançado de regeneração no Município de Viçosa, Minas Gerais, no período de agosto de 2009 a fevereiro de 2011.

\section{MATERIAL E MÉTODOS}

\section{1. Área de estudo}

Este trabalho foi desenvolvido na Estação de Pesquisas, Treinamento e Educação Ambiental Mata do Paraíso, pertencente à Universidade Federal de Viçosa, situada no Município de Viçosa, na Zona da Mata de Minas Gerais, a 229 km da capital Belo Horizonte. A área possui 194 ha e está a uma altitude média de 650 m (Figura 1).

De acordo com a classificação de Köppen, o clima da região é classificado como temperado quente, com verões chuvosos e invernos frios e secos (Cwb). A precipitação média anual e a umidade relativa ficam em torno de 1.268,2 mm e 81\%, respectivamente, sendo a temperatura média anual igual a $20^{\circ} \mathrm{C}$, conforme dados obtidos na estação meteorológica local, no período de 1968 a 2010.

Os solos da Mata do Paraíso são classificados como Latossolo Vermelho-Amarelo distrófico nas áreas com perfis convexos, câmbicos nos topos das elevações em função da existência de horizonte B de pequena espessura, argissolos nas áreas de perfis côncavos e nos terraços e hidromórficos aluviais no leito maior (CORREA, 1984).

\subsection{Metodologia}

Os dados foram obtidos no período de agosto de 2009 a fevereiro de 2011. As leituras foram feitas, quando possível, logo após cada evento de chuva. Assim, cada coleta constitui uma ou mais precipitações. As medições foram realizadas com o auxílio de provetas e baldes graduados.

A precipitação em aberto foi obtida por medições realizadas em um pluviômetro de PVC com área de captação de $167 \mathrm{~cm}^{2}$, instalado em uma torre acima do 

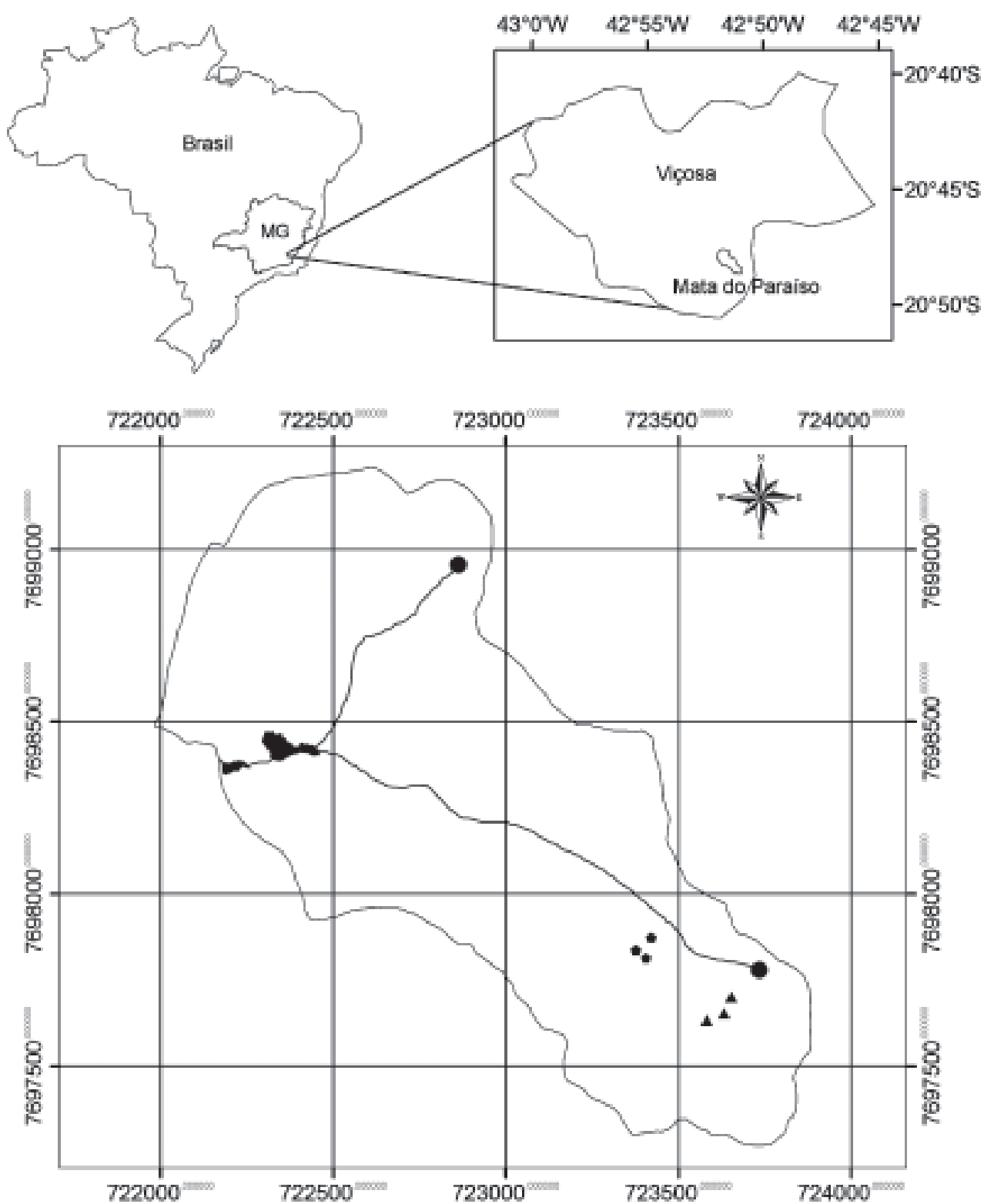

\section{Legenda}
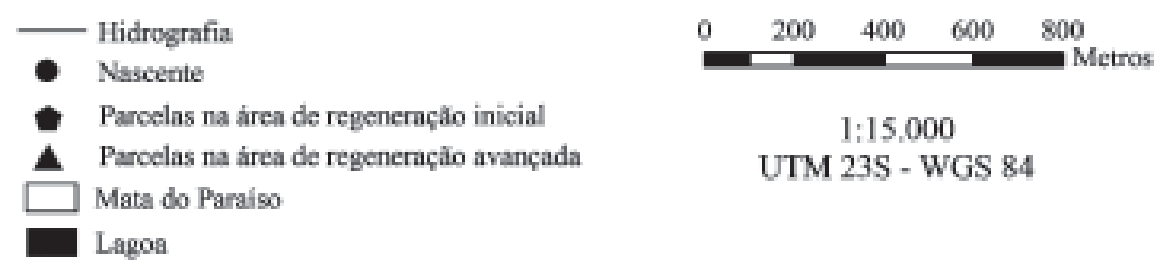

$1: 15,000$

UTM 23S - WGS 84

Lagoa

Figura 1 - Delimitação da Mata do Paraíso, Viçosa-MG, 2009-2011.

Figure 1 -Demarcation of Mata do Paraíso forest, Viçosa-MG, 2009-2011. 
dossel da floresta. A precipitação em aberto foi calculada de acordo com a equação 1 :

$$
P A=\left(\frac{V}{A}\right) \times 10
$$

em que $P A$ é a precipitação em aberto (mm), $V$ é o volume do pluviômetro (mL) e $A$ é a área de captação do pluviômetro $\left(\mathrm{cm}^{2}\right)$.

Para quantificação da precipitação interna (PI), foram lançadas seis parcelas de 20 m x 20 m, três na área de regeneração inicial e três na área de regeneração avançada, espaçadas $10 \mathrm{~m}$ entre si. Cada parcela é composta por 25 pluviômetros distanciados 5,0 m entre si. Os pluviômetros foram construídos com PVC e garrafas "pets", com área individual de captação central de 75,4 cm$^{2}$ e 81,7 cm², respectivamente. Para o cálculo da precipitação interna da parcela, utilizou-se a equação 2 .

$$
P I=\frac{\sum(V / A) \times 10}{25}
$$

em que $P I$ é a precipitação interna (mm), $V$ é o volume de cada pluviômetro (mL) e $A$ é a área de captação de cada pluviômetro $\left(\mathrm{cm}^{2}\right)$.

Para medição do escoamento pelo tronco (Et) foi demarcado, dentro de cada parcela de precipitação interna, uma subparcela de $10 \times 10 \mathrm{~m}$, onde foram adaptados coletores à base de poliuretano nos troncos das árvores com circunferência $\geq 15 \mathrm{~cm}$ medidas a $1,30 \mathrm{~m}$ sobre o nível do solo (CAP). A água da chuva foi direcionada com o uso de uma mangueira de 5/8" afixada aos coletores, para recipientes individuais de plástico. Para o cálculo do escoamento pelo tronco da parcela, utilizou-se a equação 3.

$$
E t=\frac{\sum V}{A S}
$$

em que Et é o escoamento pelo tronco (mm), $V$ é o volume de cada coletor (L) e AS é a área da sub-parcela $\left(100 \mathrm{~m}^{2}\right)$.

A precipitação efetiva foi obtida pela soma da precipitação interna e do escoamento pelo tronco, de acordo com a equação 4 .

$$
P E=P I-E t
$$

em que $P E$ é a precipitação efetiva $(\mathrm{mm}), P I$ é a precipitação interna (mm) e Et é o escoamento pelo tronco $(\mathrm{mm})$.

As perdas por interceptação foram obtidas pela diferença entre a precipitação em aberto e a precipitação efetiva, de acordo com a equação 5:

$$
I=P A-P E
$$

em que $I$ é a interceptação ( $\mathrm{mm}$ ), $P A$ é a precipitação em aberto (mm) e $P E$ é a Precipitação efetiva (mm).

Com uma fita diamétrica, mediu-se a circunferência a 1,30 m sobre o nível do solo (CAP) de todas as árvores com $C A P \geq 15 \mathrm{~cm}$, presentes em cada parcela de precipitação interna, para a obtenção do $D A P$ (diâmetro a 1,3 m de altura) e posterior estimação da área basal em cada estágio de regeneração.

Os resultados de precipitação efetiva, precipitação interna, escoamento pelo tronco e interceptação foram analisados estatisticamente através do teste $t$ de Student ao nível de 5\% de probabilidade e submetidos à análise de regressão utilizando-se o software Statistica (STATSOFT, INC, 2011).

\section{RESULTADOS}

Em algumas medições, a precipitação interna média da parcela foi maior que a precipitação em aberto. Isso, em tese, seria impossível acontecer devido à interceptação da chuva pelo dossel florestal, porque parte da precipitação total é evaporada e parte atinge o solo através do escoamento pelo tronco e gotejamento (MOURA et al., 2009); utilizou-se número menor de medições na análise dos dados. A distribuição espacial irregular das chuvas, aliada à forma alongada da bacia (OLIVEIRA JUNIOR, 2006) e à distância entre o pluviômetro em aberto e as parcelas, pode ter contribuído para tal ocorrência. Essa incoerência também foi descrita por Moura et al. (2009) e Izidio et al. (2013), em estudos de interceptação.

A precipitação interna atingiu um volume total de 1274,26 mm na área de regeneração inicial e 1102,84 mm na área de regeneração avançada (Tabela 1). Esses valores corresponderam, respectivamente, a 84,39 e 73,04\% da precipitação em aberto. Observou-se ao longo do período de estudos, que o escoamento pelo tronco contribui com a menor parte da água da chuva que atingiu o solo da mata, com 10,38 mm para o estágio 
Tabela 1 - Valores mensais (mm) de precipitação em aberto (PA), precipitação efetiva (PE), precipitação interna (PI), escoamento pelo tronco (Et) e perdas por interceptação (I) em estágio inicial (i) e avançado (a) de regeneração. Mata do Paraíso, Viçosa-MG, 2009-2011.

Table 1 - Monthly values ( $\mathrm{mm}$ ) for the open area precipitation (PA), net precipitation (PE), throughfall (PI), stem flow (Et) and losses by interception (I) in the initial (i) and advanced (a) stages of regeneration. Mata do Paraíso, Viçosa-MG, 2009-2011.

\begin{tabular}{|c|c|c|c|c|c|c|c|c|c|}
\hline Mês & PA & $\mathrm{PEi}$ & $\mathrm{PEa}$ & PIi & PIa & Eti & Eta & Ii & Ia \\
\hline ago/09 & 13,60 & 10,17 & 9,66 & 10,13 & 9,57 & 0,04 & 0,09 & 3,43 & 3,94 \\
\hline set/09 & 32,50 & 24,06 & 20,88 & 23,87 & 20,43 & 0,18 & 0,45 & 8,44 & 11,62 \\
\hline out/09 & 125,20 & 107,48 & 95,52 & 106,83 & 93,82 & 0,65 & 1,70 & 17,72 & 29,68 \\
\hline nov/09 & 110,70 & 93,55 & 86,26 & 93,00 & 84,74 & 0,55 & 1,52 & 17,15 & 24,44 \\
\hline dez/09 & 110,74 & 91,17 & 78,78 & 90,56 & 77,08 & 0,61 & 1,70 & 19,57 & 31,96 \\
\hline jan/10 & 87,72 & 73,11 & 64,57 & 72,53 & 63,12 & 0,58 & 1,45 & 14,61 & 23,15 \\
\hline fev/10 & 54,64 & 40,99 & 32,92 & 40,75 & 32,30 & 0,24 & 0,62 & 13,65 & 21,72 \\
\hline $\mathrm{mar} / 10$ & 118,82 & 104,76 & 88,05 & 104,05 & 85,99 & 0,71 & 2,07 & 14,06 & 30,77 \\
\hline $\mathrm{abr} / 10$ & 22,17 & 15,41 & 11,94 & 15,35 & 11,60 & 0,07 & 0,34 & 6,76 & 10,23 \\
\hline mai/10 & 39,22 & 30,76 & 27,80 & 30,62 & 27,07 & 0,14 & 0,73 & 8,46 & 11,42 \\
\hline jun/10 & 0 & 0 & 0 & 0 & 0 & 0 & 0 & 0 & 0 \\
\hline jul/10 & 0 & 0 & 0 & 0 & 0 & 0 & 0 & 0 & 0 \\
\hline ago/10 & 0 & 0 & 0 & 0 & 0 & 0 & 0 & 0 & 0 \\
\hline set/10 & 23,00 & 19,89 & 19,09 & 19,72 & 18,31 & 0,17 & 0,78 & 3,11 & 3,91 \\
\hline out/10 & 66,70 & 54,21 & 48,49 & 53,76 & 46,89 & 0,45 & 1,61 & 12,49 & 18,21 \\
\hline nov/10 & 360,69 & 317,53 & 280,80 & 314,25 & 273,10 & 3,28 & 7,70 & 43,16 & 79,89 \\
\hline dez/10 & 214,53 & 186,65 & 168,60 & 184,96 & 163,97 & 1,69 & 4,62 & 27,88 & 45,93 \\
\hline jan/11 & 71,66 & 65,46 & 56,26 & 64,88 & 54,30 & 0,58 & 1,96 & 6,20 & 15,40 \\
\hline fev/11 & 58,07 & 49,45 & 41,81 & 49,00 & 40,55 & 0,45 & 1,27 & 8,62 & 16,26 \\
\hline Total & 1509,96 & 1284,64 & 1131,45 & 1274,26 & 1102,84 & 10,38 & 28,61 & 225,32 & 78,51 \\
\hline
\end{tabular}

de regeneração inicial e 28,61 mm para o estágio de regeneração avançada (Tabela 1) representando, respectivamente, a 0,69 e 1,89\% da precipitação em aberto.

A precipitação efetiva no estágio de regeneração inicial foi de 1284,64 mm, valor que representa 85,08\% da precipitação em aberto. Já para o estágio de regeneração avançada a precipitação efetiva foi de 1131,45 mm, correspondendo a 74,93\% da precipitação em aberto (Tabela 1). A interceptação pelo dossel florestal foi de 225,32 para o estágio de regeneração inicial e 378,51 mm para o estágio de regeneração avançada (Tabela 1). Esses valores corresponderam, respectivamente, a 14,92 e 25,07 \% da precipitação em aberto.

Os dados de precipitação em aberto, de precipitação efetiva, de precipitação interna do escoamento pelo tronco e da interceptação, nos dois estágios de regeneração, foram submetidos à análise de regressão linear, cujos resultados estão na Figura 2.

\section{DISCUSSÃO}

Em algumas medições a precipitação interna média da parcela foi maior que a precipitação em aberto. Como isso em tese seria impossível de acontecer, devido à interceptação da chuva pelo dossel florestal, porque parte da precipitação total é evaporada e parte atinge o solo através do escoamento pelo tronco e gotejamento (MOURA et al., 2009), utilizou-se um número menor de medições na análise dos dados. A distribuição espacial irregular das chuvas, aliada à forma alongada da bacia (OLIVEIRA JUNIOR, 2006) e a distância entre o pluviômetro em aberto e as parcelas, pode ter contribuído para tal ocorrência. Essa incoerência também foi descrita por Moura et al. (2009) e Izidio et al. (2013), em estudos de interceptação.

\subsection{Precipitação interna}

Por meio dos resultados da Tabela 2, pode-se observar que a precipitação interna no estágio de regeneração inicial é maior que no estágio de regeneração avançada 
em todas as classes de precipitação. No entanto, pelo teste t a 5\% de probabilidade, essas duas áreas não tiveram diferenças significativas quanto à precipitação interna, embora existam diferenças na densidade populacional entre os estágios de regeneração.
Alves et al. (2007), estudando a precipitação interna nesse mesmo local, também não encontraram diferenças significativas entre os dois estágios de regeneração. Os mesmos autores encontraram valores de precipitação interna de 79,05 e 80,86\% da precipitação em aberto,
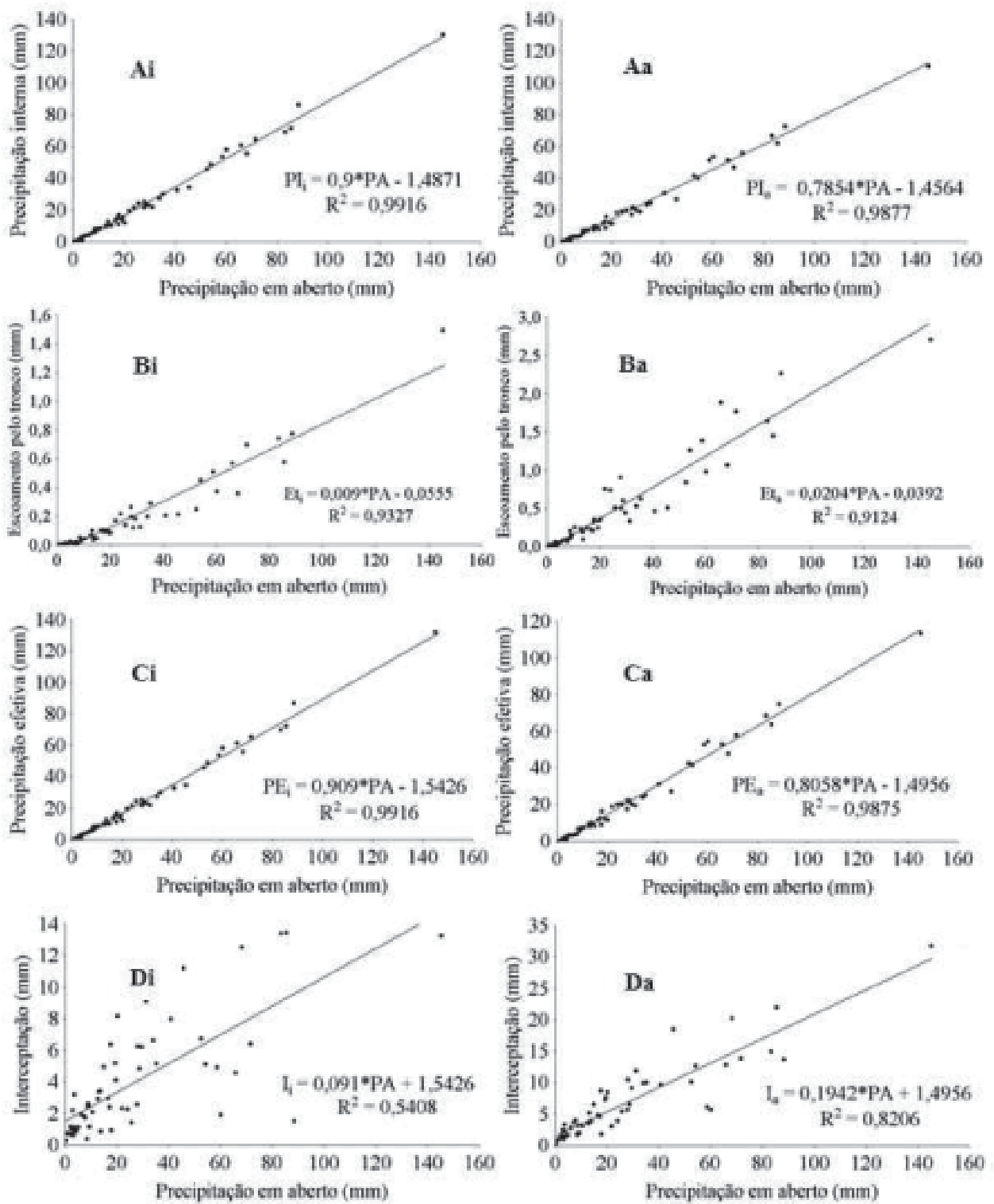

Figura 2 - Relação entre a precipitação em aberto e a precipitação interna (A), o escoamento pelo tronco (B), a precipitação efetiva (C) e a interceptação (D) no estágio inicial (i) e avançado (a) de regeneração. Mata do Paraíso, Viçosa-MG, 2009-2011.

Figure 2 - Relationship between gross precipitation and through fall (A), stem flow (B), net precipitation (C) and interception (D) at the initial (i) and advanced (a) stages of regeneration. Mata do Paraíso, Viçosa-MG, 2009-2011. 
Tabela 2 - Valores médios (mm) de precipitação em aberto (PA), precipitação efetiva (PE), precipitação interna (PI), escoamento pelo tronco (Et) e perdas por interceptação (I) em estágio inicial (i) e avançado (a) de regeneração, em função da classe de precipitação. Mata do Paraíso, Viçosa-MG, 2009-2011.

Table 2 - Mean values ( $\mathrm{mm}$ ) of gross precipitation (PA), net precipitation (PE), throughfall (PI), stem flow (Et) and loss interception (I) in the initial (i) and advanced (a) stages of regeneration, in function of the precipitation class. Mata do Paraíso, Viçosa-MG, 2009-2011.

\begin{tabular}{|c|c|c|c|c|c|c|c|c|c|c|}
\hline Classe de precipitação (mm) & Frequência & PA & PEi & PEa & PIi & PIa & Eti & Eta & Ii & Ia \\
\hline$<2,5$ & 4 & 1,04 & 0,30 & 0,26 & 0,30 & 0,26 & 0,00 & 0,00 & 0,74 & 0,78 \\
\hline $2,5-5,0$ & 9 & 3,21 & 1,95 & 1,43 & 1,95 & 1,40 & 0,00 & 0,03 & 1,26 & 1,78 \\
\hline $5,0-10,0$ & 8 & 7,72 & 6,07 & 5,09 & 6,04 & 4,98 & 0,03 & 0,11 & 1,65 & 2,63 \\
\hline $10,0-20,0$ & 12 & 15,61 & 12,30 & 10,51 & 12,22 & 10,26 & 0,08 & 0,25 & 3,31 & 5,10 \\
\hline $20,0-30,0$ & 8 & 25,79 & 21,52 & 19,18 & 21,35 & 18,58 & 0,17 & 0,60 & 4,27 & 6,61 \\
\hline $30,0-40,0$ & 3 & 33,54 & 26,57 & 22,90 & 26,36 & 22,40 & 0,21 & 0,50 & 6,97 & 10,64 \\
\hline $40,0-50,0$ & 2 & 43,23 & 33,63 & 29,12 & 33,42 & 28,63 & 0,21 & 0,49 & 9,60 & 14,11 \\
\hline $50,0-60,0$ & 3 & 55,19 & 49,58 & 45,55 & 49,18 & 44,39 & 0,40 & 1,16 & 5,61 & 9,64 \\
\hline $60,0-70,0$ & 3 & 64,82 & 58,48 & 51,87 & 58,05 & 50,56 & 0,43 & 1,31 & 6,34 & 12,95 \\
\hline$>70,0$ & 5 & 94,90 & 85,29 & 75,63 & 84,43 & 73,66 & 0,86 & 1,97 & 9,61 & 19,27 \\
\hline
\end{tabular}

nas áreas de regeneração inicial e avançada, respectivamente. As diferenças obtidas entre esses dois trabalhos podem ser devidas à condução do experimento e, ou, à amostragem da área. Além disso, o ingresso e morte de espécies arbóreas ao longo dos anos também podem ter contribuído para a diferença entre os estudos.

A precipitação interna apresentou elevada relação com a precipitação em aberto, com o menor valor de coeficiente de determinação $\left(R^{2}\right)$ igual a 0,9877 no estágio de regeneração avançado (Figura 2). Essa tendência linear também pode ser observada na Tabela 2, em que se verifica aumento da precipitação interna com o também aumento da precipitação em aberto. Essas observações estão de acordo com as relatadas por Togashi et al. (2012) em estudos de interceptação de chuvas na Mata Atlântica e por Oliveira et al. (2011) em estudos de interceptação da chuva na Floresta Amazônica.

A partir da equação linear (Figura 2), foi possível estimar a capacidade de retenção da água da chuva pela copa das árvores. Verificou-se que apenas valores acima de 1,65 e 1,85 mm, respectivamente nos estágios inicial e avançado de regeneração, permitem o registro de precipitação interna. Valor semelhante $(1,59 \mathrm{~mm})$ foi estimado por Oliveira et al. (2008), estudando a precipitação efetiva e a interceptação das chuvas em floresta de terra firme no Pará.

\subsection{Escoamento pelo tronco}

Segundo Oliveira et al. (2011), os valores de escoamento pelo tronco, apesar de pequenos, devem ser considerados de grande importância, pois a baixa velocidade e quantidade de água que chega ao solo facilitam a infiltração, reduzindo o escoamento superficial.

Observa-se na Tabela 2 que o escoamento pelo tronco somente se manifestou a partir da classe de precipitação superior a $2,5 \mathrm{~mm}$, e no estágio de regeneração inicial esse valor só começou a ser registrado a partir de uma classe de precipitação superior a 5,0 mm. É de se esperar que na área de regeneração avançada, por ser mais densamente povoada, produza maior escoamento pelo tronco, uma vez que a interceptação da chuva no estágio avançado é maior que no estágio de regeneração inicial. Dessa forma, quanto maior a área basal do local, maior será a interceptação e, consequentemente, maior o escoamento pelo tronco.

Pela equação de regressão linear (Figura 2), estimou-se que o escoamento pelo tronco só ocorrerá a partir de uma precipitação em aberto superior a 6,17 mm no estágio de regeneração inicial e 1,92 mm no estágio de regeneração avançada. Esses valores foram coerentes com os observados no campo (Tabela 2). Resultados relativamente próximos foram obtidos por Shinzato et al. (2011), que estimaram $11,0 \mathrm{~mm}$ para um fragmento secundário de Mata Atlântica e 6,6 mm para um plantio de eucalipto. Essas diferenças indicaram a peculiaridade de cada local, onde o tipo de vegetação, características climatológicas locais, no que diz respeito, principalmente, a intensidade e intervalo entre precipitações, além do grau de umidade da cobertura, interferem diretamente no volume escoado pelo tronco (LIMA; LEOPOLDO, 1999).

Revista Árvore, Viçosa-MG, v.37, n.4, p.619-627, 2013 
Pelo teste t a 5\% de probabilidade, verificou-se diferenças significativas entre os dois estágios de regeneração, demonstrando que o escoamento pelo tronco na área de regeneração avançada é estatisticamente maior que no estágio de regeneração inicial.

\subsection{Precipitação efetiva}

O percentual de precipitação efetiva encontrado neste estudo está dentro do intervalo obtido em trabalhos anteriores desenvolvidos nesse mesmo local, como os 87,60\% observados por Castro et al. (1983). Oliveira Junior e Dias (2005) obtiveram no estágio de regeneração inicial precipitação efetiva de $81,70 \%$, enquanto Alves et al. (2007), no estágio de regeneração avançada, registraram precipitação efetiva de $81,63 \%$. As diferenças obtidas entre os trabalhos podem ser devidas ao período de estudos, ao desenvolvimento do experimento, à amostragem ou, ainda, à mudança nas estruturas horizontal e vertical da floresta ocorridas ao longo desses anos.

Outros valores de precipitação efetiva observados em diversos ecossistemas obtiveram resultados próximos aos encontrados neste trabalho, como: $87,80 \%$ em povoamentos de eucalipto (LIMA, 1976), 72,80\% em espécies arbustivas no Nordeste do México (NÁVAR; BRYAN, 1990), 78,94\% em florestas de terra firma no Amazonas (OLIVEIRA et al., 2011) e 82,40\% em vegetação de Caatinga no semiárido cearense (IZIDIO et al., 2013).

Na Figura 2, verifica-se que a precipitação efetiva possui alta correlação com a precipitação em aberto, como indica o modelo de regressão linear. Essa alta correlação mostra que a precipitação efetiva é influenciada, principalmente, pela quantidade de chuva que precipita sobre a floresta. Estatisticamente, pelo teste t a 5\% de probabilidade, não houve diferença significativa quanto à precipitação efetiva nos dois estágios de regeneração.

\subsection{Interceptação}

Os valores relativos de interceptação encontrados na área de estudo são próximos aos 12,40\% observados por Castro et al. (1983) em fragmento de Mata Atlântica, 21,50\% observados por Oliveira et al. (2011) na Amazônia e 17,9\% verificados por Izidio et al. (2013) em vegetação de Caatinga no semiárido cearense. Em geral, as menores classes de precipitação proporcionaram as maiores interceptações, como pode ser observado na Tabela 2.
Isso significa que o dossel florestal possui capacidade máxima de retenção de água da chuva. Dessa forma, pequenas precipitações não são capazes de saturar completamente a copa das árvores.

Observa-se, na Figura 2, que a correlação entre a interceptação e a precipitação em aberto possui dependência reduzida, principalmente no estágio de regeneração inicial, representada com $\mathrm{R}^{2}=0,5408$. Essa baixa interdependência é observada na Tabela 2, em que a interceptação, em certas classes de altura pluviométrica, não acompanha o aumento da precipitação em aberto, demonstrando que outros fatores, além da quantidade de chuva, interferem na interceptação. Esses fatores podem estar relacionados com a intensidade da chuva, a presença de vento e, ainda, o intervalo entre as chuvas (NALON; VELLARDI, 1993; MOURA et al., 2009). A interceptação, nos dois estágios de regeneração, foi analisada estatisticamente através do teste t a 5\% de probabilidade e apresentou diferenças significativas.

\section{CONCLUSÕES}

Com base nos resultados, pode-se concluir que o escoamento pelo tronco e a interceptação da chuva, no período estudado, foram maiores no estágio de regeneração avançada, enquanto a precipitação efetiva e a precipitação interna, maiores no estágio de regeneração inicial.

A precipitação efetiva, a precipitação interna e o escoamento pelo tronco seguiram tendência linear em relação ao total precipitado, sendo a precipitação interna a variável que mais contribuiu para a quantidade de água no solo.

A interceptação foi a que demonstrou correlação mais baixa em relação à precipitação em aberto, indicando a influência de outros fatores relacionados à interceptação. Além disso, a interceptação não apresentou aumento proporcional às classes mais altas de precipitação, evidenciando que o dossel florestal possui capacidade máxima de retenção da água de chuva.

\section{REFERÊNCIAS}

ALVES, R. F. et al. Avaliação da precipitação efetiva de um fragmento de Mata Atlântica em diferentes estágios de regeneração no município de Viçosa, MG. Revista Ambiente e Água, v. 2, n.1, p.83-93, 2007. 
ARCOVA, F. C. S.; CICCO, V.; ROCHA, P. A. B. Precipitação efetiva e interceptação das chuvas por floresta de Mata Atlântica em uma microbacia experimental em Cunha São Paulo. Revista Árvore, v.27, n.2, p.257-262, 2003.

BALBINOT, R. et al. O papel da floresta no ciclo hidrológico em bacias hidrográficas. Revista Ambiência, v.4, n.1, p.131-149, 2008.

CASTRO, P. S. et al. Interceptação da chuva por mata natural secundária na região de Viçosa MG. Revista Árvore, v.7, n.1, p.76-89, 1983.

CORREA, G. F. Modelo de evolução e mineralogia da fração argila de solos do planalto de Viçosa, MG. 1984. 87f. Dissertação (Mestrado em Solos) - Universidade Federal de Viçosa, Viçosa, MG, 1984.

LIMA, P. R. A.; LEOPOLDO, P. R. Interceptação de chuva por mata ciliar na região central do Estado de São Paulo. Energia na

Agricultura, v.14, n.3, p.25-33, 1999.

LIMA, W. P. Estudos de alguns aspectos quantitativos e qualitativos do balanço hídrico em plantações de Eucalyptus e Pinus. 1975. 111f. Tese (Doutorado em Ciências Florestal) - Escola Superior de Agricultura "Luiz de Queiroz", Piracicaba, 1975.

LIMA, W. P. Interceptação da chuva em povoamentos de eucalipto e de pinheiro. IPEF, n.13, p.75-90, 1976.

MOURA, A. E. S. S. et al. Interceptação das chuvas em um fragmento de floresta da Mata Atlântica na Bacia do Prata, Recife, PE. Revista Árvore, v.33, n.3, p.461-469, 2009.

NALON, M. A.; VELLARDI, A. C. V. Estudo do balanço hídrico nas escarpas da serra do mar, região de Cubatão, SP. Revista do Instituto Florestal, v.5, n.1, p.39-58, 1993.
NÁVAR, J.; BRYAN, R. Interception loss and rainfall redistribution by three semi-arid growing shrubs in northeastern Mexico. Journal of Hydrology, v.115, n.1, p.51-63, 1990.

OLIVEIRA JUNIOR, J. C. Precipitação efetiva em Floresta Estacional Semidecidual na reserva Mata do Paraíso, Viçosa, Minas Gerais. 2006. 72f. Dissertação (Mestrado em Ciência Florestal) - Universidade Federal de Viçosa, Viçosa, MG, 2006.

OLIVEIRA JUNIOR, J. C.; DIAS, H. C. T. Precipitação efetiva em fragmento secundário da Mata Atlântica. Revista Árvore, v.29, n.1, p.915, 2005.

OLIVEIRA, L. L. et al. Precipitação efetiva e interceptação em Caxiuanã, na Amazônia Oriental. Acta Amazonica, v.38, n.4, p.723-732, 2008.

OLIVEIRA, L. L. et al. Sazonalidade e interceptação da chuva na Floresta Nacional em Caxiuanã - Amazônia Oriental. Scientia Plena, v.7, n.10, p.1-14, 2011.

SHINZATO, E. T. et al. Escoamento pelo tronco em diferentes povoamentos florestais na Floresta Nacional de Ipanema em Iperó, Brasil. Scientia Forestalis, v.39, n.92, p.395-402, 2011.

IZIDIO, N. S. C. et al. Interceptação da chuva pela vegetação da caatinga em microbacia no semiárido cearense. RevistaAgro@mbiente, v.7, n.1, p.44-52, 2013.

STATSOFT, INC. Statistica (data analysis software system). version 7. 2004. www.statsoft.com.

TOGASHI, H. F.; MONTEZUMA, R. C. M.; LEITE, A. F. Precipitação incidente e fluxo de atravessamento das chuvas em três estágios sucessionais de Floresta Atlântica no maciço da Pedra Branca, Rio de Janeiro. Revista Árvore, v.36, n.5, p.907-917, 2012. 
